\section{Antimicrobial stewardship in daily practice: Managing an important resource}

Nicole Le Saux; Canadian Paediatric Society, Infectious Diseases and Immunization Committee

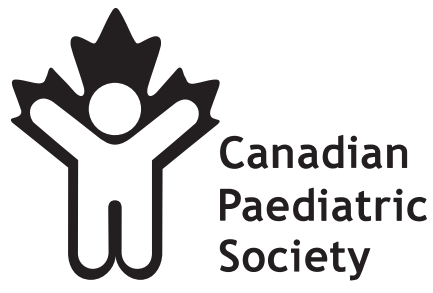

\begin{abstract}
Antimicrobial stewardship is a recent concept that embodies the practical, judicious use of antimicrobials to decrease adverse outcomes from antimicrobials while optimizing the treatment of bacterial infections to reduce the emergence of resistant pathogens. The objectives of the present statement are to illustrate the principles of antimicrobial stewardship and to offer practical examples of how to make antimicrobial stewardship part of everyday hospital and outpatient practice. Vital components of antimicrobial stewardship include appropriate testing to diagnose whether infections are viral or bacterial, and using clinical follow-up rather than antibiotics in cases in which the child is not very ill and uncertainty exists. Other specific, important actions include questioning whether positive urine cultures are contaminated when there is no evidence of pyuria or inflammatory changes, and obtaining a chest radiograph to support a diagnosis of bacterial pneumonia. Optimizing the choice and dosage of antimicrobials also reduces the probability of clinical failures and subsequent courses of antimicrobials. A list of common clinical scenarios to promote stewardship is included.
\end{abstract}

Key Words: AOM; C difficile; E coli; Pneumonia; Superbugs; UTIs

\section{La gestion des antimicrobiens dans la pratique quotidienne : administrer une ressource importante}

La gestion des antimicrobiens est un concept récent qui recouvre l'utilisation pratique et judicieuse des antimicrobiens pour en réduire les effets indésirables tout en optimisant le traitement des infections bactériennes afin de limiter l'émergence d'agents pathogènes. Le présent document de principes vise à exposer les principes de la gestion des antimicrobiens et à donner des exemples pratiques pour les intégrer à la pratique quotidienne en milieu hospitalier et en milieu ambulatoire. Les tests pertinents pour diagnostiquer si les infections sont d'origine virale ou bactérienne et le suivi clinique de préférence aux antibiotiques lorsque l'enfant n'est pas très malade et que l'incertitude persiste sont les éléments essentiels de la gestion des antimicrobiens. Parmi les autres mesures importantes et spécifiques, il faut se demander si les cultures d'urine positives sont contaminées en l'absence de pyurie ou de changements inflammatoires et effectuer une radiographie pulmonaire pour étayer un diagnostic de pneumonie bactérienne. L'optimisation du choix et de la dose d'antimicrobiens réduit également la probabilité d'échecs cliniques et de traitements subséquents. Une liste des scénarios cliniques fréquents afin de promouvoir la gestion des antimicrobiens est également présentée. ntimicrobial stewardship is defined as a collection of interven$A_{\text {tions geared toward optimizing the prescribing of antimicrob- }}$ ials, and includes the appropriate selection, dosing, route and duration of antimicrobial therapy with the goal of optimizing patient outcomes and decreasing adverse events related to antimicrobial therapy.(1)

Few drugs aside from antimicrobials can lay claim to providing cures for diseases. The dramatic and lifesaving impacts of antimicrobial therapy in the treatment of major illnesses, such as bacterial pneumonia, typhoid fever, urinary tract infections (UTIs), sepsis and endocarditis, are still observed every day, but may be in peril in the future.

The objectives of the present statement are to illustrate the principles of antimicrobial stewardship and to offer practical examples of how to make antimicrobial stewardship part of everyday hospital and outpatient practice. The need for antimicrobial stewardship stems from the knowledge that overusing antimicrobials has increased the risk of children carrying antimicrobial-resistant bacteria and contributing to the increasing incidence of Clostridium difficile gastrointestinal infections. Examples of the relationship between the overuse of antimicrobials and emerging resistance include macrolide use and resistance in Streptococcus pneumoniae, and ampicillin use and resistance in Escherichia coli.(2-4) Furthermore, resistant bacteria and C difficile can be shed into the environment and, as such, be transmitted from person to person, thus representing a risk to society in general. Other benefits of antimicrobial stewardship for patients and for organizations are the decrease in adverse events and superinfections related to antimicrobial use, and the cost savings associated with lowering antimicrobial use. Common situations of overuse include prescribing for uncomplicated upper respiratory tract infections, chronic serous otitis media, "bronchitis" or the empirical use of antibiotics for pharyngitis. Without changing prescribing practices and controlling access to 'over-thecounter' antimicrobials globally we can expect increasing antimicrobial resistance and the emergence of 'superbugs' that will threaten the well-being of people around the world.

Additionally, recent long-term studies of the effect of antimicrobial therapy on the human microbiome have suggested a possible association between previous antimicrobial therapy and the development of obesity and allergies.(5-7) Such findings and others could revolutionize our understanding of the long-term impact of antimicrobials on the human host. Being better 'stewards' of antimicrobials not only helps to preserve their use in treating infections, but also decreases the unintentional harms caused by using antimicrobials unwisely. Intervening and demonstrating antimicrobial stewardship will continue to be a required organizational practice for health care organizations in Canada.(8)

This article was previously published as a Canadian Paediatric Society Position Statement in the May 2014 issue of Paediatrics $\mathcal{E}$ Child Health $(2014 ; 19[5]: 261-70)$.

Correspondence: Canadian Paediatric Society, 2305 St Laurent Boulevard, Ottawa, Ontario K1G 4J8. E-mail info@cps.ca, website www.cps.ca 
As a prescriber, improving stewardship means deciding whether a patient truly needs antimicrobials and, if so, selecting the most appropriate antimicrobial, dose, route and duration of therapy with two related goals: optimizing therapy and minimizing the risk of adverse events. Current antimicrobial stewardship programs in hospitals range from committee influence on the formulary to 'persuasive' influences on prescribing such as prospective audit and feedback from pharmacists and physicians specifically trained in infectious diseases. Individual prescribers, however, are also responsible for applying the same principles to all patients, including those in outpatient settings.

Some principles of stewardship, such as watchful waiting or narrowing the antimicrobial spectrum, may not be applicable to patients who are immunosuppressed or otherwise susceptible to severe infections (eg, asplenic patients or those with congenital immunodeficiency syndromes), or to newborns or infants for whom empirical antimicrobials should be considered in clinical settings where localizing signs of infection are subtle.

\section{USE CLINICAL JUDGEMENT AND TEST JUDICIOUSLY}

Clinical judgment based on a patient's age, history and physical examination (including vital signs) is critically important for deciding whether there is an infection and judging its severity. When signs or symptoms suggest bacteremia, meningitis or other serious or lifethreatening infection, appropriate cultures should be taken and effective antimicrobials, based on potential pathogens, initiated immediately. Similarly, a 'septic work-up' and cultures of specimens should be restricted to patients with a reasonable suspicion of a bacterial infection. Determining the results of culture testing and reassessing the clinical situation to adjust or stop antimicrobial therapy are important steps in the management process.

Testing in an office practice may be more challenging depending on proximity to a laboratory or a diagnostic imaging centre. Unless antimicrobials are required immediately, delaying antimicrobial therapy is reasonable in a stable, mildly ill child for whom a viral etiology is most probable (eg, a wheezing, febrile but otherwise reasonably well infant during respiratory syncytial virus season). However, prolonged or worsening symptoms in a presumed viral illness should prompt reevaluation because a small proportion of patients may develop a secondary bacterial infection.

In other situations, confirming a viral etiology is important for therapeutic or epidemiological purposes (such as early in the influenza season or for patients who are hospitalized). During the viral season, even in outpatient settings, timely testing for influenza in a moderately ill child with or without a pneumonia or with risk factors for severe disease may be important to starting treatment with antiviral agents active against influenza (eg, oseltamivir).

In the setting of pharyngitis with nonviral symptoms, a throat swab or a rapid antigen detection test for group A streptococci should be used to confirm streptococcal pharyngitis. If culture based, waiting $24 \mathrm{~h}$ to $48 \mathrm{~h}$ for the result before prescribing an antibiotic is reasonable when the child is not severely ill. An excellent review on this subject is available.(9)

When considering acute otitis media (AOM), accuracy of the diagnosis (fluid behind an inflamed tympanic membrane in a child who has acute ear pain) should be paramount. If the child is older than six months of age, has uncomplicated, unilateral AOM with mild signs and symptoms, follow-up is accessible and caregivers understand the rationale, it is reasonable to treat with analgesics alone and adopt the 'watch and wait' approach for $48 \mathrm{~h}$ to $72 \mathrm{~h}$ after onset of symptoms to see if pain and fever resolve. Persistent symptoms should be treated with antimicrobials because the likelihood of a bacterial etiology is higher.(10)

Confirming a diagnosis of lobar pneumonia with a chest radiograph, if possible, is also recommended before starting empirical therapy.(11) Studies indicate that clinical assessment alone leads to overdiagnosis and overtreatment in many cases.(12) If a pneumonic infiltrate is not observed or if the radiograph is consistent with bronchiolitis, careful follow-up without antimicrobial therapy is warranted. Similarly, when a site is clinically infected and shows purulent drainage, it is equally important to take cultures.

In the vast majority of circumstances, it is more prudent for patients with suspected or proven viral illnesses to have access to timely follow-up rather than prescribing antibiotics initially. Good clinical acumen and the course of illness remain the mainstays when deciding whether a viral or a bacterial process is at work.

\section{TREAT INFECTION, NOT CONTAMINATION}

The contamination of specimens is common, especially with urine and wound samples. Without symptoms and signs of infection, there is a significant probability that the isolated bacteria was simply at the site when the specimen was collected or when it reached the testing laboratory and has contaminated the specimen. To prevent contamination, ensure that urine specimens are collected appropriately (by catheter or a clean catch midstream), even in newborns. The diagnosis of a UTI requires the presence of some signs of infection (ie, fever, or dysuria, or frequency in older ages) and some laboratory evidence of inflammation (eg, white blood cells, leukocyte esterase or nitrites in the urine) in addition to the presence of a significant amount of a uropathogen such as E coli.(13) Generally, the treatment of positive cultures when there are no signs of infection is incorrect, and avoiding this practice is an important principle of antimicrobial stewardship.

Taking a pharyngeal culture in an asymptomatic person or in a child with cough and rhinorrhea is not wise because the culture only demonstrates that group A streptococcus is colonizing or present at the site without causing infection; this should not be a reason for treatment. Similarly, the presence of methicillin-resistant Staphylococcus aureus (MRSA) isolated from nasal or rectal specimens should not routinely trigger the start of antibiotic regimens for decolonization or treatment.

On the other hand, antibiotic prophylaxis is indicated in specific settings, such as defined close contacts of individuals with invasive meningococcal, group A streptococcal or Haemophilus influenzae type b (Hib) disease.

\section{TAKE A CAREFUL HISTORY OF POTENTIAL ANTIBIOTIC SIDE EFFECTS AND, IF POSSIBLE, CONFIRM AN ANTIMICROBIAL ALLERGY}

An immunoglobulin (Ig)-E-mediated allergy usually manifests as urticaria, pruritus, bronchospasm, angioedema or hypotension within $1 \mathrm{~h}$ of drug administration. Patients with an IgE-mediated allergy to a penicillin should avoid penicillins in the future. However, the crossreactivity with a cephalosporin is extremely low (2\%) even with a penicillin allergy.(14) If the history is suggestive of an IgE-mediated reaction to penicillin, penicillin skin testing should be performed by an allergist. A negative test will allow for penicillin use in the future and the 'label' of penicillin allergy can be removed.(15) A history of $\operatorname{IgE}$-mediated allergy in a parent is not a reason to avoid that antibiotic in the child.

A history of serious non-IgE-mediated reactions, such as StevensJohnson syndrome or toxic epidermal necrolysis attributed to an antibiotic, is a contraindication to using related antibiotics in the future.

The most common side effects of using an antibiotic are nonurticarial maculopapular rashes or gastrointestinal symptoms such as diarrhea. Many of these symptoms are probably viral in etiology or idiosyncratic reactions to the drug, and not an allergy. Because these are not IgE-mediated side effects, the child can be given that antibiotic in the future, often permitting use of antimicrobials with a narrower spectrum of activity. 


\section{LABORATORIES SHOULD PRODUCE LOCAL, AGE-SPECIFIC ANTIBIOGRAMS TO GUIDE ANTIBIOTIC CHOICES FOR SELECTED INFECTIONS}

Aside from empirical therapy for meningitis and other life-threatening infections for which guidelines recommend broad spectrum coverage pending cultures, the local or regional antibiogram is a useful tool. The local antibiogram is a compilation of susceptibility patterns for common isolated bacteria, such as $S$ pneumoniae, $S$ aureus or E coli, in a local area and, as such, is useful for predicting susceptibility of bacteria. For example, in some areas, $>90 \%$ of $E$ coli in UTIs in children may be susceptible to a first-generation cephalosporin, making this antibiotic a reasonable choice for empirical outpatient treatment.(16) Using antibiotic resistance patterns from other countries or based on predominantly adult patients may overestimate resistance (eg, the prevalence of penicillin-resistant $S$ pneumoniae is higher in adults than in children in Canada) and encourages unnecessarily broad-spectrum antimicrobial use. Similarly, multidrug-resistant pathogens in UTIs are uncommon in most children and the use of quinolones should be restricted to cases for which there is documented resistance of a pathogen to other agents. Quinolones should not be used as empirical therapy in this scenario.

Regional laboratories should produce and disseminate age-specific antibiograms on a routine basis for use by clinicians. In turn, physicians should become familiar with the usual prevalence of resistance for common pathogens to guide empirical therapy. Although cultures should still be performed, the need to 'de-escalate' therapy would probably occur less often.

\section{NARROW THE SPECTRUM OF ANTIMICROBIALS WHEN A CAUSATIVE ORGANISM IS IDENTIFIED}

Because initial therapy is most often empirical, it is incumbent on the physician to de-escalate therapy when the pathogen is found to be susceptible to a narrower-spectrum agent (eg, for UTIs) if this is practical. If $S$ aureus is susceptible to oxacillin, then cloxacillin or cephalexin (rather than a second- or third-generation cephalosporin or a macrolide) is the drug of choice. Most community-acquired respiratory infections are due to pathogens ( $S$ pneumoniae and group A streptococcus) which have retained susceptibility to penicillins.

\section{OPTIMIZE THE DOSING OF ANTIMICROBIALS} TO OBTAIN MAXIMAL BENEFIT

Dose optimization for antimicrobials is often a neglected part of therapy and the choice among antibiotics should not be made solely on the basis of convenient dosing.(17) Generally, prescribers should always use the higher end of the recommended dose range for a specific infection to treat children with normal kidney and liver function.

Some antimicrobials (such as aminoglycosides) exhibit 'dose-dependent' killing. They typically have a maximal effect when the initial dose is high with less frequent dosing. Aminoglycosides administered once every $24 \mathrm{~h}$, rather than on a traditional dosing schedule of every $8 \mathrm{~h}$, is recommended for all children with normal renal function beyond the neonatal period (with some centres also using it for neonates). By contrast, most oral penicillins and cephalosporins (beta-lactams) have a very short halflife of approximately $1 \mathrm{~h}$. However, for maximal effectiveness (bacterial killing), the amount of beta-lactam at the site of infection should be higher than the concentration needed to inhibit the pathogen at least one-half of the day. Otherwise, bacterial multiplication will continue during trough periods. This is known as 'time-dependent' killing.

For a nonserious infection such as AOM, using the beta-lactam amoxicillin in a twice-per-day regimen is reasonable if the dose is sufficiently high $(75 \mathrm{mg} / \mathrm{kg} /$ day to $90 \mathrm{mg} / \mathrm{kg} /$ day). However, for more serious infections, such as pneumonia, cellulitis, cervical adenitis, sinusitis or abscess, a beta-lactam should be given three or four times per day. $(11,17,18)$ Physicians should explain to parents why a dosing schedule of three or four times per day has a higher chance of cure compared with a twice-per-day regimen in these situations.

\section{USE THE SHORTEST RECOMMENDED COURSE OF THERAPY FOR UNCOMPLICATED INFECTIONS}

The optimal duration of therapy for most infections is not known. Shorter courses of antimicrobials are associated with fewer adverse events and less development of resistance compared with longer courses.(19)

The length of recommended penicillin therapy for streptococcal pharyngitis is still 10 days. For other infections, however, some data support shorter courses. In children older than two years of age, the recommended duration of therapy for uncomplicated AOM that has failed a 'watch and wait' approach is five days rather than seven to 10 days. For uncomplicated pneumonia in otherwise healthy children, seven days, rather than 10 to 14 days, is reasonable. $(10,11,18,20)$ For UTIs, recommendations range from seven to 14 days.(13) Individualizing therapy to use the shorter recommended courses should take into consideration the extent of illness at presentation and the rapidity of clinical improvement after starting antimicrobials.

\section{TAKE CARE NOT TO CHANGE OR PROLONG ANTIMICROBIAL THERAPY UNNECESSARILY}

Knowing that patients with infections such as lobar pneumonia, cervical adenitis or pyelonephritis, for example, can take three days or more to defervesce completely should not be regarded as evidence of treatment failure when other signs indicate some improvement in clinical condition. Cellulitis also may take a day or so to improve. In most cases, escalating therapy to broader-spectrum coverage is not warranted when there is no microbiological reason to do so. In cases for which there is no clinical evidence of infection or when there is no response to antimicrobial therapy, it is useful to reassess the presumed diagnosis and consider noninfectious or other (fungal or viral) etiologies for the symptoms. Other conditions associated with fever include Kawasaki disease, neoplasms, juvenile inflammatory arthritis, inflammatory bowel disease and recurrent fever syndromes.

\section{PROMOTE VACCINATIONS TO REDUCE THE LIKELIHOOD OF CLINICAL DISEASE}

Vaccines prevent infections and, consequently, decrease antimicrobial use. The routine use of conjugated pneumococcal vaccine has lowered the incidence of otitis media and pneumonia, helping to reduce antimicrobial use significantly.(21) Similarly, administering influenza vaccine to children has been shown to decrease febrile illnesses and thus, potentially, antibiotic use. $(22,23)$ Publicly funded varicella vaccine has not only lowered the incidence of varicella but has also prevented associated secondary cellulitis.(24)

For other simple ways to minimize the use of antibiotics in practice, see Box 1.

\section{CONCLUSIONS}

Antimicrobial stewardship is a complex interplay of art, science and common sense. Many variables, such as when to start antibiotics, optimal dosing, reassessment of patients, determining what is and what is not a bacterial infection and when the patient can stop antibiotics, should be considered in using these valuable medications. Careful consideration of our use of antimicrobials must become an integral part of practice.

Note: Information for parents, 'How to make sure antibiotics are the right choice', can be accessed at www.caringforkids.cps.ca.

ACKNOWLEDGEMENTS: This position statement has been reviewed by representatives of the Association of Medical Microbiology and Infectious Disease Canada and by the Community Paediatrics, Acute Care, Drug Therapy and Hazardous Substances, and Fetus and Newborn Committees of the Canadian Paediatric Society. 


\section{BOX 1}

Ten ways to promote antimicrobial stewardship in your paediatric practice

1. Always document a child's vital signs, the physical examination and why you are using an antibiotic in your notes. This forces more mindful reflection on the decision and is of great practical value when others see the child in follow-up. Schedule a clinical follow-up instead of starting antibiotics for patients who are not very ill but may have a bacterial infection.

2. Detail a suspected drug reaction as much as possible, to determine whether the history meets criteria for a true allergy or not. Consultation with an allergist may be useful for some patients.

3. Ensure that the minimum diagnostic criteria for the diagnosis of a urinary tract infection are met before starting antibiotics. Send a urinalysis, a urine microscopy and a urine culture (clean catch or catheter specimen). Vaginitis from soap or bubble bath is commonly confused with urinary tract infections in preschool-age girls.

4. Infectious syndromes that are typically due to Streptococcus pneumoniae or group A streptococcus (GAS) are best treated with betalactam antibiotics (such as penicillin), not with azithromycin or other macrolides (eg, clarithromycin). If you need coverage for Staphylococcus aureus primarily, use cloxacillin (if the child can swallow pills) or cephalexin. If the child has a high risk for methicillinresistant $S$ aureus and the lesions are typical, drainage alone may work and/or trimethoprim-sulfamethoxazole orally, or vancomycin intravenously for severe infections, may be used empirically.

5. Do not perform throat cultures on children with sore throat who have any features of a cold (rhinorrhea, cough or hoarseness of voice). A positive culture for GAS in this setting almost always indicates that the child is a carrier and will not benefit from antibiotics. Do not perform follow-up throat swabs on individuals who have completed therapy for GAS pharyngitis.

6. ALWAYS use the correct weight-based dose and optimize the frequency and duration of the antibiotic to achieve maximal benefit from therapy. Most outpatient antibiotic prescriptions should be for five to seven days. Many cases of mild-to-moderate acute otitis media will resolve on their own without antibiotic therapy.

7. Ampicillin intravenously or oral amoxicillin (three times per day) are the empirical drugs of choice for community-acquired pneumonia. If there is poor response, consider complications of pneumonia or other diagnoses before changing antibiotics. Treatment with a macrolide should be reserved for clinical presentations consistent with Mycoplasma or Chlamydia pneumonia.

8. A chest radiograph has high sensitivity in the diagnosis of pneumonia and, whenever practical, should be performed before starting antibiotics.

9. Children who present with wheezing almost never need antibiotics because the diagnosis is usually asthma in older children or viral bronchiolitis in infants.

10. Know the typical bacteria that cause common outpatient infections. Most skin and soft tissue infections are due to $S$ aureus or GAS and will respond to narrow-spectrum antibiotics such as cephalexin. Clinically infected sites that are visibly draining or purulent should be cultured. Minor skin and wound infections may be managed with topical therapy.

\section{REFERENCES}

1. Dellit TH, Owens RC, McGowan JE Jr, et al. Infectious Diseases Society of America and the Society for Healthcare Epidemiology of America guidelines for developing an institutional program to enhance antimicrobial stewardship. Clin Inf Dis 2007;44(2):159-77.

2. Jones RN, Sader HS, Mendes RE, Flamm RK. Update on antimicrobial susceptibility trends among Streptococcus pneumoniae in the United States: Report of ceftaroline activity from the SENTRY Antimicrobial Surveillance Program (19982011). Diagn Microbiol Inf Dis 2013;75(1):107-9.

3. Karlowsky JA, Hoban DJ, Decorby MR, Laing NM, Zhanel GG. Fluoroquinolone-resistant urinary isolates of Escherichia coli from outpatients are frequently multidrug resistant: Results from the North American Urinary Tract Infection Collaborative Alliance-Quinolone Resistance study. Antimicrob Agents Chemother 2006;50(6):2251-4.

4. Golding GR, Persaud N, Levett PN, et al. Characterization of Escherichia coli urinary tract infection isolates in remote northern Saskatchewan communities: The Northern Antibiotic Resistance Partnership. Diagn Microbiol Inf Dis 2012;74(3):242-7.

5. Johnson CL, Versalovic J. The human microbiome and its potential importance to pediatrics. Pediatrics 2012;129(5):950-60.

6. Hernández E, Bargiela R, Diez MS, et al. Functional consequences of microbial shifts in the human gastrointestinal tract linked to antibiotic treatment and obesity. Gut Microbes 2013;4(4):306-15.

7. Kuo CH, Kuo HF, Huang CH, Yang SN, Lee MS, Hung CH. Early life exposure to antibiotics and the risk of childhood allergic diseases: An update from the perspective of the hygiene hypothesis. J Microbiol Immunol Infect 2013;46(5):320-9.

8. Accreditation Canada. Required Organizational Practices Handbook 2014, 33: www.accreditation.ca/sites/default/files/rophandbook-2014-en.pdf (Accessed March 4, 2014).

9. Shulman ST, Bisno AL, Clegg HW, et al. Clinical practice guideline for the diagnosis and management of group A streptococcal pharyngitis: 2012 update by the Infectious Diseases Society of America. Clin Infect Dis 2012;55(10):1279-82.

10. Forgie S, Zhanel G, Robinson J; Canadian Paediatrics Society, Infectious Diseases and Immunization Committee. Management of acute otitis media. Paediatr Child Health 2009;14(7):457-64.

11. Le Saux N, Robinson J; Canadian Paediatric Society, Infectious Diseases and Immunization Committee. Pneumonia in healthy
Canadian children and youth: Practice points for management. Paediatr Child Health 2011;16(7):417-20.

12. Zimmerman DR, Kovalski N, Fields S, Lumelsky D, Miron D. Diagnosis of childhood pneumonia: Clinical assessment without radiological confirmation may lead to overtreatment. Pediatr Emerg Care 2012;28(7):646-9.

13. Roberts KB; American Academy of Pediatrics, Subcommittee on Urinary Tract Infection, Steering Committee on Quality Improvement and Management. Urinary tract infection: Clinical practice guideline for the diagnosis and management of the initial UTI in febrile infants and children 2 to 24 months. Pediatrics 2011;128(3):595-610.

14. Unger NR, Gauthier TP, Cheung LW. Penicillin skin testing: Potential implications for antimicrobial stewardship. Pharmacotherapy 2013;33(8):856-67.

15. Robinson JL, Hameed T, Carr S. Practical aspects of choosing an antibiotic for patients with a reported allergy to an antibiotic. Clin Infect Dis 2002;35(1):26-31.

16. Dahle KW, Korgenski EK, Hersh AL, Srivastava R, Gesteland PH. Clinical value of an ambulatory-based antibiogram for uropathogens in children. J Pediatric Infect Dis Soc 2012;1(4):333-6.

17. Ambrose PG, Bhavnani SM, Rubino CM, et al. Pharmacokineticspharmacodynamics of antimicrobial therapy: It's not just for mice anymore. Clin Infect Dis 2007;44:79-86.

18. Bradley JS, Byington CL, Shah SS, et al. Executive summary: The management of community-acquired pneumonia in infants and children older than 3 months of age; Clinical practice guidelines by the Pediatric Infectious Diseases Society and the Infectious Diseases Society of America. Clin Infect Dis 2011;53(7):617-30.

19. Guillemot D, Carbon C, Balkau B, et al. Low dosage and long treatment duration of beta-lactam: Risk factors for carriage of penicillinresistant Streptococcus pmeumoniae. JAMA 1998;279(5):365-70

20. Greenberg D, Givon-Lavi N, Sadaka Y, Ben-Shimol S, Bar-Ziv J, Dagan R. Short-course antibiotic treatment for community-acquired alveolar pneumonia in ambulatory children: A double-blind, randomized, placebo-controlled trial. Pediatr Infect Dis J 2014;33(2):136-42.

21. Wilby KJ, Werry D. A review of the effect of immunization programs on antimicrobial utilization. Vaccine 2012;30(46):6509-14. 
22. Nichol KL, Mendelman PM, Mallon KP, et al. Effectiveness of live, attenuated intranasal influenza virus vaccine in healthy, working adults: A randomized controlled trial. JAMA 1999;282(2):137-44.

23. Kwong JC, Maaten S, Upshur RE, Patrick DM, Marra F. The effect of universal influenza immunization on antibiotic prescriptions: An ecological study. Clin Infect Dis 2009;49(5):750-6.
24. Tan B, Bettinger J, McConnell A, et al. The effect of funded varicella immunization programs on varicella-related hospitalizations in IMPACT centres, Canada, 2000-2008. Pediatr Infect Dis J 2012;31(9):956-63.

\section{CPS INFECTIOUS DISEASES AND IMMUNIZATION COMMITTEE}

Members: Robert Bortolussi MD (past Chair); Natalie A Bridger MD; Jane C Finlay MD (past member); Susanna Martin MD (Board Representative); Jane C McDonald MD; Heather Onyett MD; Joan L Robinson MD (Chair); Marina I Salvadori MD (past member); Otto G Vanderkooi MD

Liaisons: Upton D Allen MBBS, Canadian Pediatric AIDS Research Group; Michael Brady MD, Committee on Infectious Diseases, American Academy of Pediatrics; Charles PS Hui MD, Committee to Advise on Tropical Medicine and Travel (CATMAT), Public Health Agency of Canada; Nicole Le Saux MD, Immunization Monitoring Program, ACTive (IMPACT); Dorothy L Moore MD, National Advisory Committee on Immunization (NACI); Nancy ScottThomas MD, The College of Family Physicians of Canada; John S Spika MD, Public Health Agency of Canada

Consultant: Noni E MacDonald MD

Principal author: Nicole Le Saux MD

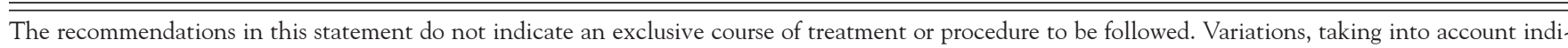
vidual circumstances, may be appropriate. All Canadian Paediatric Society position statements and practice points are reviewed on a regular basis. Retired statements are removed from the website. Please consult the Position Statements section of the CPS website (www.cps.ca) for the full-text, current version. 


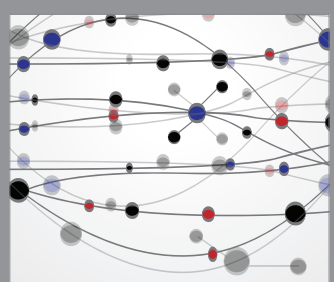

The Scientific World Journal
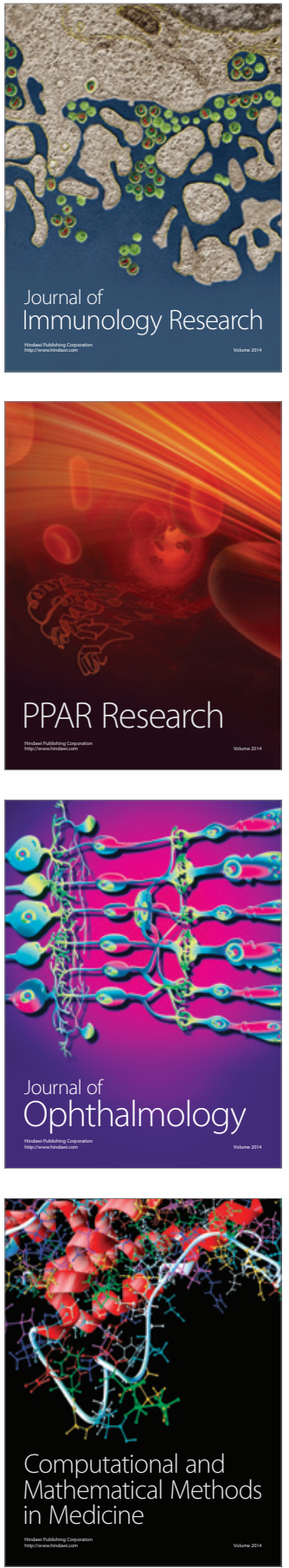

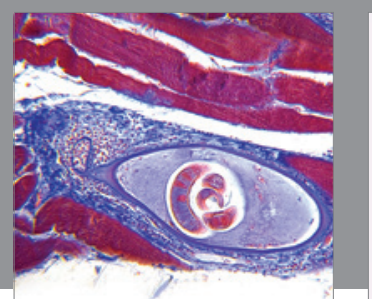

Gastroenterology Research and Practice

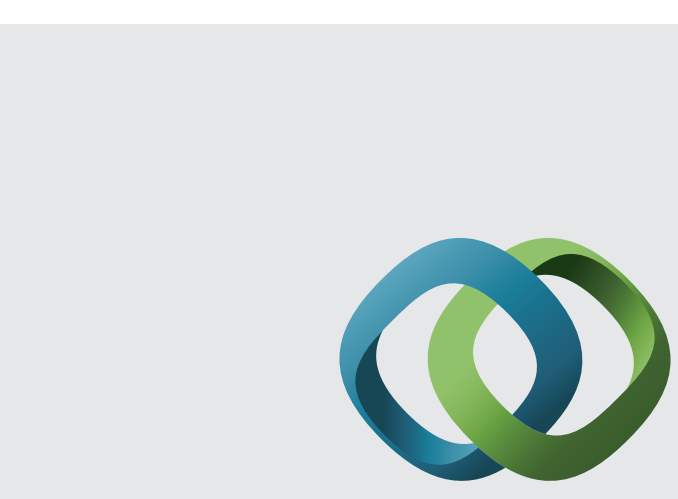

\section{Hindawi}

Submit your manuscripts at

http://www.hindawi.com
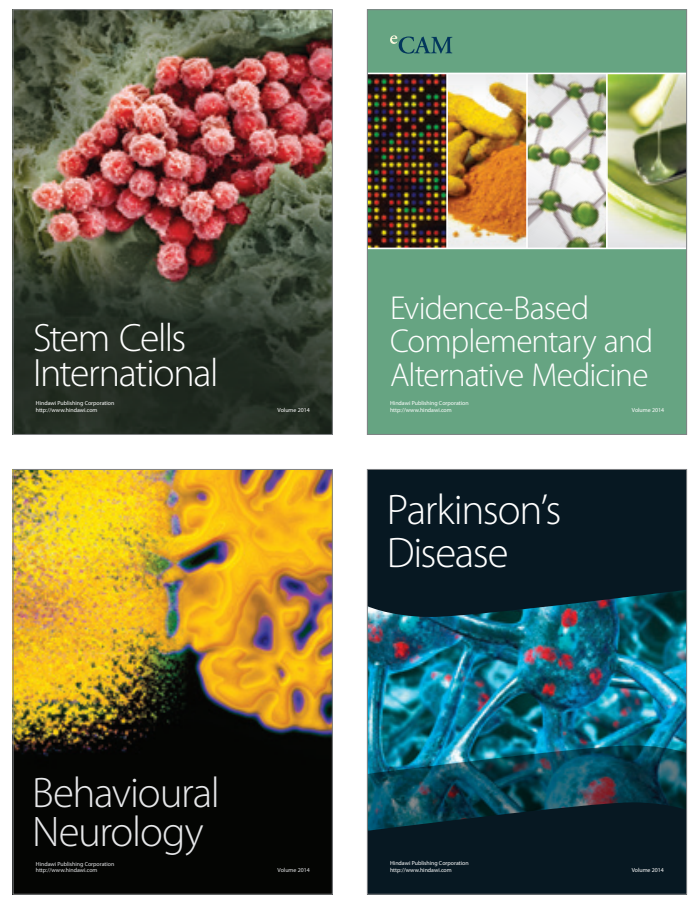
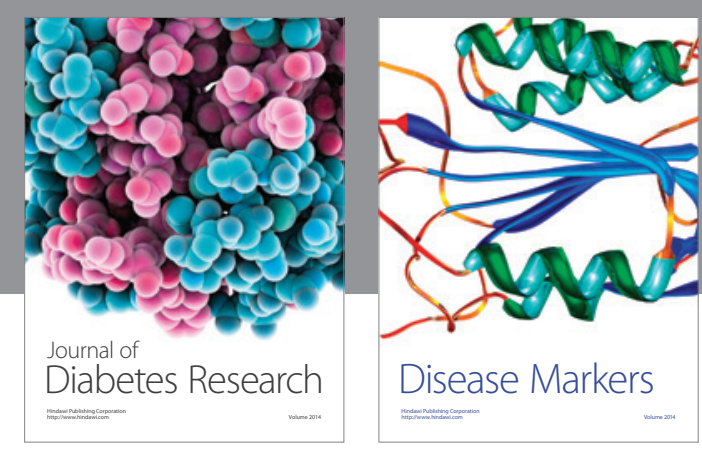

Disease Markers
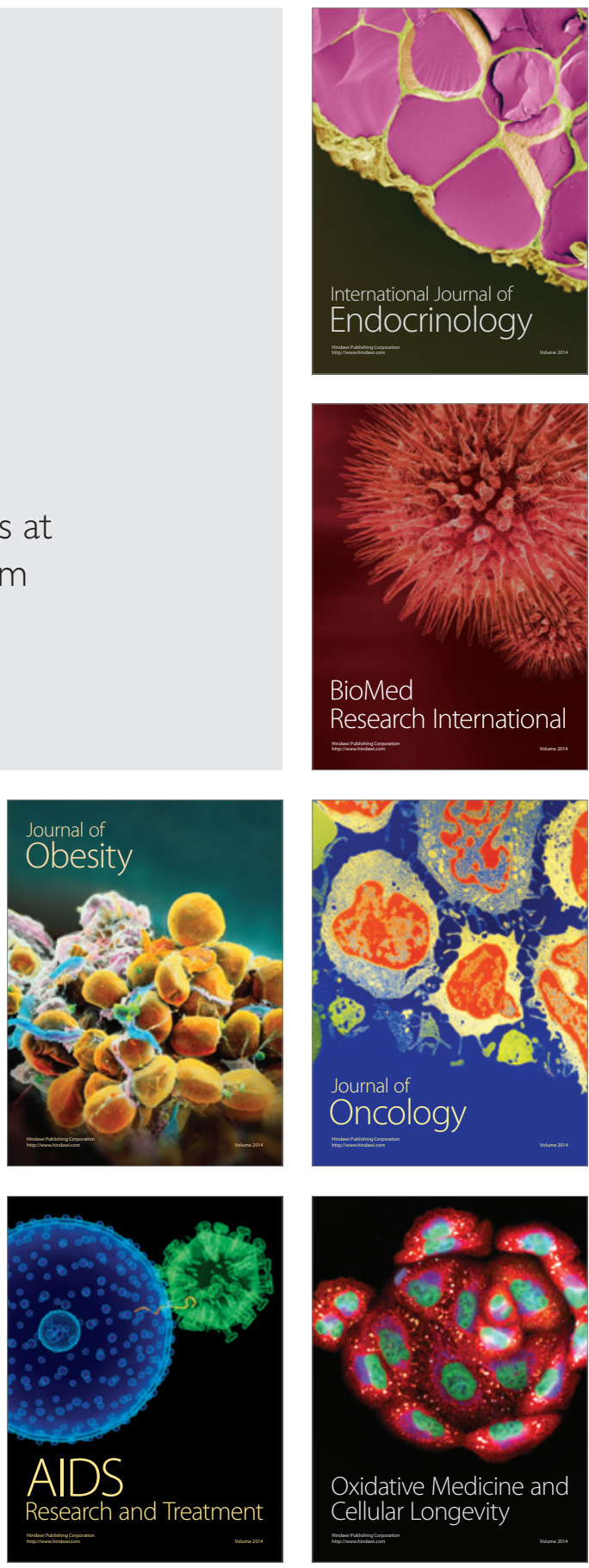